\title{
RURAL WOMEN ADOPTION OF ENVIRONMENTAL PRACTICES IN MENUFIYA GOVERNORATE
}

\author{
Salama ${ }^{1}$, F.A.; Farahat A. Mohamed ${ }^{1}$ and Eman M. Osman ${ }^{1}$ \\ 1- Department of Agricultural Extension and Rural Sociology College of Agriculture, \\ Menufiya University, Shebin El-Kom, Egypt
}

Keywords: Adoption of Agricultural Innovations, Rural women, Environmental Behavior, Environmental Awareness

\section{ABSTRACT}

This study aimed basically at identifying the level of rural women adoption of environmental practices in Menufiya Governorate. This main obective was achieved throw the followinge subobjectives : determining the environmental knowledge level of rural women, identifying the dgree of rural women application of environmental practices, determining the factors which correlated with each of the environmental knowledge level and dgree of rural women application of environmental practiece. The study was carried out in two villeges in Menufiya Governorate, the first villege was
Monshiat Bakhaty which belongs to Shebien Elkom district and the sconede villege was Sahel Elgawaber which belongs to El shohadaa district. 100 rural women were selected randomly from each village. The study findings were: the environmental knowledge level was high as $83.5 \%$ from respondents. About $47 \%$ from respondents were applying the environmental practices. There were four independent variables (social participation, culturel cosmoplitness, geographical cosmoplitness, age) explained together $16.3 \%$ of the total variance of the environmental knowledge level. There were six independent variables (family monthly incom, environmental situation at the village, cultural cosmoplitness, family education, geographical cosmoplitness, environmental knowledge) explained together $55.5 \%$ of the total variance of the environmental application dgree.

(Received June 3, 2009)

(Accepted June 29, 2009) 